\title{
La Ilustración Alemana Y Los Dilemas De La SchwärmereI
}

\author{
[The Enlightenment And The Dilemmas Of The Schwärmerei]
}

Martin RodrIguez Baigorria *

\begin{abstract}
Resumen: En el siguiente artículo nos proponemos rastrear algunos precedentes de la discusión en torno al sentido de la Ilustración (1783-1784) a partir de las controversias linguísticas alrededor del fenómeno entusiasta. En este sentido, la necesidad de distinguir entre "Enthusiasmus" y "Schwärmerei" -debatida por autores como Wieland, Herder, y Lessing - ya anticipaba en buena medida los dilemas inherentes a la auto-comprensión del proyecto ilustrado. Durante la década del ochenta, la pluralización de los significados del término "Schwärmerei" conducirá entonces a aquella crisis producida en torno a los sentidos de la palabra "Aufklärung". En disputa se hallaban distintas concepciones de la racionalidad y la autonomía subjetiva.
\end{abstract}

Palabras Clave: Ilustración, Entusiasmo, Schwärmerei, intelectuales alemanes
ABstract: In this article we intend to show some precedents of the discussion on the meaning of the Enlightenment (1783-1784) from some linguistic controverses around the phenomena entusiasta. So comes the need to distinguish between "Enhusiasmus" and "Schwärmerei" - talked by authors like Wieland, Herder, and Lessing - that had already been antecipated by the dilemmas inherent to auto-understanding of the project Enlightenment. During the eighties, pluralizations of meanings of the term "Schwärmerei" lead to that crisis grown around the senses of the term "Aufklärung". We had disputing concepts as rationality and autonomia subjective.

KEYWORDS: Enlightenment, enthusiasm, Schwärmerei, german intelectuals

\section{Ourante el último cuarto del siglo XVIII, la Ilustración alemana (Aufklärung) parecía imponerse en el mundo de las} letras a través de la Popularphilosophie. Dicho movimiento representaba la contraparte a la Ilustración francesa encabezada Voltaire (1694-1778), Jean le Rond d'Alembert (1717-1783), y Denis Diderot (1713-1784). Surgido durante la regencia del ilustrado Federico II (1712-1786), sus centros principales eran Berlín y la universidad de Göttingen, dirigida por Gerlach A. Münchhaussen (1688-1770). Entre sus miembros principales se hallaban Johann. E Biester (1749-1816), Johann A. Eberhard (1739-1809), Friedrich Nicolai (1733-1811),

* Professor Doutor en la Universidad de Buenos Aires, Argentina. Docente de Literatura del Siglo 19. Este artigo es resultado de pesquisas vinculadas a proyetos financiados por: German Acadmic Exchange Service (DAAD), Consejo Nacional de Investicaciones Cientíticas, Universidad de Buenos Aires (UBA), Berlin Freie Universität (FU).m@ailto: martin.rodriguezbaigorria@gmail.com 
Friedrich Gedike (1754-1803), y Christian Garve (1748-1792). En la variedad de sus obras y autores, la Aufklärung se había comprendido a sí misma como un esfuerzo emancipatorio orientado a la autodeterminación individual mediante la crítica del dogmatismo religioso, el debate racional, y la difusión de las nuevas ideas científicas. La "ilustración" era entendida como una educación del público (Publikum, Öffentlichkeit): una propedéutica para la participación en el

60 debate social, que pudiera a su vez tomar distancia de la superstición religiosa por medio del cultivo de la razón y el buen el gusto. Uno de sus objetivos fundamentales era así expandir dichos principios más allá de los límites del mundo académico, buscando la atención del público y los grupos sociales no cultivados (Beiser, 1987, p. 165, Outram, 2009, pp. 9-19).

En este contexto, el debate por el sentido de la Ilustración iniciado en las páginas del Berliner Monatschrift puede ser abordado desde muchos puntos de vista: ya sea desde la perspectiva de los vínculos de dicho movimiento con el absolutismo, su interés por la educación del pueblo y la solución de problemas prácticos, a partir de la pregunta por su papel en la difusión de las ideas revolucionarias, o desde la perspectiva de su relación con la religión y el lenguaje filosófico. Desde un punto de vista histórico-conceptual este último aspecto no carece de interés: tal como veremos, el propio carácter universalista de los ideales propugnados por la Ilustración no dejaba de poner en peligro su afán crítico-emancipatorio al estar sujeto a múltiples interpretaciones. Dichos sentidos heterogéneos formaban parte a su vez de las implicancias democratizadoras del proceso ilustrado, también puesto en marcha a partir de una nueva y formidable expansión de la cultura impresa.

Un ejemplo singular de estas tensiones histórico-culturales puede hallarse en los usos de dos términos fuertemente vinculados a la historia del misticisimo protestante. Nos referimos a las palabras "Enthusiasmus" y "Schwärmerei". Si bien este último vocablo era muchas veces utilizado de manera homóloga a la expresión "entusiasmo" ("Enthusiasmus"), las connotaciones peyorativas de dicho término fueron objeto de usos cambiantes que trascendieron su ámbito religioso original. Surgido de la polémica religiosa mantenida por Lutero contra los anabaptistas y otras sectas rebeldes durante la 
Reforma, el término se convirtió en una referencia obligada dentro de la discusión teológico-doctrinal, para luego volverse un vocablo de uso corriente tanto en la filosofía como en la crítica literaria. Tras este término peyorativo aparecían frecuentemente englobados aquellas formas de "delirio fanático", comunes en las corrientes místicas de los siglos XVII y XVIII, reñidas con el dogma ortodoxo. Pero, al mismo tiempo, la fuerte carga negativa de término "Schwärmerei" dejaba traslucir a su vez toda una serie de connotaciones casi siempre asociadas negativamente a las distintas representaciones del orden social. Buena parte de las implicancias más controversiales del fenómeno entusiasta giraban así en torno a las connotaciones peyorativas y estigmatizadoras imantadas por el término luterano: proveniente del verbo "schwärmen" ("zumbar"), la palabra evocaba el zumbido insistente de un enjambre de abejas o una jauría de perros alejada de su hogar. O en otros términos: una imagen amorfa de la comunidad, sumida en un estado de excitación y ebullición continua, opuesta por definición a toda idea de orden establecido. Por otra parte, desde un punto de vista lingüísticodiscursivo, la imagen del zumbido también remitía a la idea de un lenguaje extraño o incomprensible, capaz sin embargo de penetrar en el fuero interno del creyente con su murmullo agudo e insistente; un lenguaje disruptivo y caótico, a la vez que contagioso e incontrolable. Lutero se remitía aquí al recuerdo de las primeras comunidades cristianas; actitud comprensible si tenemos en cuenta que, al igual que en el cristianismo primitivo, el "hablar en lenguas" era una de las experiencias extáticas invocadas por los anabaptistas (Kaufmann, 2002, pp. 179-231).

Sin embargo, entre mediados del siglo XVI y XVII, las connotaciones peyorativas del término comenzaron a ser cada vez más utilizadas por el discurso racionalista. Ya tras la finalización de las "guerras de religión" (1525-1648), la explicación médica había adquirido un peso cada vez más decisivo en el seno de la polémica confesional. A finales del siglo XVII, aquellos que se declaraban como poseedores de una revelación divina, comenzaban así a ser vistos como "casos", pertenecientes al ámbito de la medicina (la teoría de la "bilis negra" expuesta entre otros por Henry More y Meric de Casaubon). De allí la palabra pasó al ámbito de la filosofía moral. Una disciplina científica muy joven -la“psicología experimental" 
(Erfahrungsseelenkunde)- desempeñará aquí un rol destacado a través de publicaciones periódicas consagradas a dicho tema, como por ejemplo, el Magazin zur Erfahrungsseelenkunde editado por Karl Philipp Moritz y Pockel entre 1783 y 1793. Apoyada por representantes prominentes de la Aufklärung berlinesa (Moses Mendelssohn, 17291786- ; el "médico-filósofo" Marcus Herz, 1747-1803), la revista se convirtió en un foro de discusión centrado en el estudio de las

62 patologías psicológicas y las desviaciones sociales de la época. El estudio de los fenómenos mentales asociados al "delirio fanático" constituía en este punto un tema de interés de carácter científico y polémico a la vez. En línea con la crítica racional, se trataba de despojar al Schwärmer del conjunto de representaciones místico-religiosas que rodeaban su figura para observarlo desde la perspectiva de un fenómeno natural, definiendo en términos neutrales y objetivos el origen de sus respectivos trastornos (Bezold, 1984, pp. 96-105).

La revista se dedicaba así a informar de manera cuatrimestral sobre distintos casos de asesinato, suicidio, Schwärmerei religiosa, y accesos hipocondríacos acaecidos en la población general. En este punto, los casos de visiones, sueños, falsas profecías, y otras clases de alucinaciones, frecuentes por igual entre los sectores altos y bajos de la escala social, constituían una de las principales temáticas de preocupación para la elite culta. De allí entonces que un interés permanente y sistemático de la revista (alentado fundamentalmente por Moritz) fuera la obtención de primeros recuerdos infantiles y experiencias oníricas. La mayoría de los testimonios del Magazin daban cuenta de sueños en los cuales aparecían señales dotadas con alguna clase de significado profético. Un hombre que tenía acceso a la fecha exacta de su muerte; una mujer que veía en estado de reposo las circunstancias violentas en las que morirá su marido, etc. Para los autores de la revista, el peligro fundamental de estas supersticiones, muchas veces arraigadas en costumbres y tradiciones populares (creencia en milagros, rituales, profecías, etc.), residía ante todo en el potencial desvanecimiento de los límites entre realidad y ficción, y por ende, a la incapacidad de juzgar los propios actos. Mediante esta combinación de moral y terapéutica se pretendía entonces advertir contra una potencial "perdida de realidad" asociada al discurso Schwärmer1x. El campo de fenómenos definidos como Schwärmerei 
había pasado a englobar no solo ya los casos de éxtasis religioso o melancolía, sino también toda clase de comportamientos reñidos con las pautas de normalidad establecidas. De manera progresiva, los usos seculares del término habían comenzado a abarcar una serie de fenómenos cada vez más diversos entre sí (Gantet, 2010, p. 450).

\section{ANTECEDENTES DE LA CRISIS ILUSTRADA: LA POLÉMICA DEL TEUTSCHE MERKUR (1776).}

Estas transformaciones semántico-culturales en torno a los usos de la palabra "Schwärmerei" ya habían sido anticipadas por una curiosa polémica acontecida en las páginas del Teutsche Merkur. En junio de 1776, el escritor y crítico Martin Wieland (1733-1813) había propiciado un debate dentro del cual tomarán parte autores renombrados como Johann G. Herder (1744-1803) y Gotthold E. Lessing (1729-1781). Su pregunta concernía a las estrategias filosóficas y morales más útiles para lidiar con la problemática entusiasta, en su nueva gama de heterogéneas expresiones:

\footnotetext{
"Frente a aquello que ellos mismos llaman Entusiasmo y Schwärmerei, ¿se promueve mayor mal antes que bien a través de los filósofos de sangre fría y los espíritus luciánicos? ¿Dentro de qué límites deben ser mantenerse estos anti-platónicos y luciánicos, con el fin de que [ellos] nos sean útiles?’2x
}

A la hora de prevenir las consecuencias perniciosas del "delirio entusiasta", ¿bastaba con la mera burla flemática a la manera del "test of ridicule" recomendado por Shaftesbury en su Letter concerning Enthusiasm (1707)? ¿O acaso ella no redundaba en una condena ex profeso con efectos meramente esterilizadores? La acusación iba dirigida también contra el estilo burlón utilizado por los deístas franceses; autores como Voltaire o el Barón d'Holbach, quienes formaban parte del selecto grupo de escritores protegidos por Fedérico el Grande (1714-1786) en la corte de Prusia. El epíteto "fillósofos de sangre fría" hacía alusión a su vez a las corrientes racionalistas cuyos orígenes se hallaban en figuras como Christian Wolff hasta llegar a los miembros de la Aufklärung berlinesa. La observación calma y juiciosa -caracterizada por su "sangre fría"- era precisamente una característica 
intelectual habitualmente ensalzada en términos positivos por autores como Nicolai, Gedike, o Biester. Estos últimos eran los principales destinatarios de la polémica. En una respuesta anónima publicada por Wieland en el Merkur, el futuro autor de Agathon se sorprendía ante el hecho de que estos "fríos" filósofos no hubieran encontrado un criterio de distinción efectivo entre ambos fenómenos - "Schwärmerei" y "Entusiasmo": "(...) - de qué espíritu son hijos? (...) Maravilloso que, a 64 pesar de todo el talento y placer por las definiciones de los filósofos de sangre fría, aún no haya disponible una definición segura, fija, útil de la que se pueda partir (...)"3x.

La polémica desatada en torno a este interrogante correspondía al nuevo clima literario surgido a partir de la aparición del Sturm und Drang y a la figura del "genio" (Genie) exaltada por los autores de este movimiento. En el texto anónimo de Wieland aparecía una caracterización rapsódica de este nuevo fenómeno literario, observado con profunda preocupación por los "filósofos de sangre fría": "Ellos suspiran por dentro lamentándose sobre un cierto fuego que en Alemania enerva a los jóvenes, que incluso hace que los hombres maduros se vuelvan jóvenes; suspiran sobre una fuerza repentina y una corriente sensual ante cuyo rapto todos caen" $4 \mathrm{x}$.

A pesar del carácter muchas veces exagerado de estas críticas, sus dudas no dejaban de ser pertinentes; ya que, desde el punto de vista de muchos de sus contemporáneos, las nuevas obras literarias surgidas del Sturm und Drang no habían pasado de alentar nuevas formas de diletantismo melancólico, cuyas manifestaciones patológicas no dejaban de reproducirse en el seno de la propia elite dirigente: los representantes más brillantes de la "teología racional" como Johann F. Jerusalem (1709-1789), Johann J. Spalding (1714-1804), o jóvenes promisorios como Johann G. Hamman (1730-1788) se habían apartado repentinamente de sus obligaciones aquejados por estados ataques depresivos (o catatónicos, en el caso de Spalding), notablemente enigmáticos para sus contemporáneos. Los desordenes mentales protagonizados por Jakob M. Lenz (1751-1792), autor de Der Hofmeister (1774) y Die Soldaten (1776), representaba un caso paradigmático, ampliamente comentado por los detractores de la nueva literatura. 
La recepción controvertida del Werther (1774) de Goethe, ampliamente reflejada en las múltiples críticas, parodias e imitaciones de la novela, era otra evidencia de este malestar cultural5x. Un contemporáneo como el célebre aforista George C. Lichtenberg (17421799) se lamentaba así de que entre los jóvenes alemanes existieran tantos "Wertherisches Schwärmern". No se trata del único juicio en este sentido. Desde la perspectiva de los críticos y comentaristas de la época (Garve, Nicolai), el protagonista de la novela encarnaba de modo paradigmático el cuadro de desórdenes anímicos típicos del "entusiasta melancólico". Vinculados a los nuevos hábitos de lectura, sus síntomas nos eran en buena medida conocidos: sentimientos frenéticos y exaltados, excentricidades, trastornos perceptivos, narcisismo, reconcentración en fantasías artificiales, expresiones carentes de mesura, huida de la realidad, falta de acción, etc. Predominaba así ante todo la preocupación creciente ante una "juventud" enferma, mientras los recurrentes rumores (no comprobados) de una ola de suicidios acaecidos entre los jóvenes estudiantes se multiplicaba en revistas y folletos populares (Pikulik 1984; Maurer, 1996). Se planteaba entonces una contradicción cada vez más notoria: si la nueva cultura editorial había ofrecido la posibilidad de refundar un nuevo espacio de discusión crítica; ella parecía ahora apenas estimular modos de expresión autoindulgentes y pasatistas, ajenos a cualquier clase de examen racional. Desde esta perspectiva, la nueva espiritualidad del Sturm und Drang no podía significar más que un retroceso en el modelo de "comunidad racional" imaginado por los ilustrados (La Vopa, Klein, 1998, pp. 85117; Conrad 2008, pp. 86-104).

Por lo que, desde el punto de vista de autores como Wieland, el círculo vicioso era así perfecto: en lugar de atraer a los nuevos misticistas hacia el sendero de la razón, el escándalo de la Popularphilosophie alienaba más a dichos individuos en sus prácticas marginales y esotéricas. De este modo, el proyecto ilustrado se cerraba sobre sí mismo y se enfrentaba al riesgo de auto-cercenar la difusión de sus propios ideales. En el contexto del surgimiento de nuevas formas de expresión literaria, la imaginación y el "genio" ya no podían ser mero objeto de una estigmatización ex profeso, surgida de la burla o los diagnósticos generalizadores utilizados por la religión y el discurso médico; sino que requerían una suerte de salvaguarda filosófica, capaz 
de mantener estas nuevas manifestaciones de la subjetividad cercanas al ámbito de la "razón" y el "sentido común". El dilema de fondo radicaba entonces en el siguiente punto: ¿cuál era el grado de subjetivismo que, desde el punto de vista de la naciente esfera pública burguesa, podría tolerar la Aufklärung alemana? (Redekop, 2000).

La pregunta postulada por Wieland se proponía resolver entonces las ambigüedades de esta coyuntura: a la luz de la defensa de la espontaneidad creadora introducida por el Sturm und Drang y la difusión de las ideas ilustradas, se volvía cada vez más necesario salvaguardar un concepto de "entusiasmo" capaz de promover las nuevas aspiraciones de autonomía individual patentizadas en las nuevas formas de expresión literarias. Se trataba de una problemática ideológico-cultural en la cual filósofos, publicistas, y escritores se hallaban comprometidos desde diversos puntos de vista. Sus diferencias concernían fundamentalmente al criterio de distinción fundamental a establecer entre "entusiasmo" y Schwärmerei, al implicar ambos términos un conjunto de connotaciones opuestas y cercanas a la vez. El debate promovido por Wieland apuntaba así a extender el círculo de influencia del pensamiento ilustrado frente a aquellos fenómenos culturales que le eran ajenos en un principio.

Ya un año antes del inicio de la polémica, esta problemática aparecía abordada por Wieland en su ensayo "Enthusiasmus und Schwärmerei" (1775); el cual proponía una distinción fundamental entre ambos términos: "Denomino Schwärmerei (...) a un repentino acaloramiento del alma frente a objetos que, o bien no se hallan en la naturaleza, o al menos no se corresponden con aquello visto por el alma embriagada"6x. En este sentido, si bien la palabra "Schwärmerei" era presentada como sinónimo de la palabra "Fanatismus"7x, el sustrato religioso original del primer término se veía reemplazado por su definición médico-antropológica: "Schwärmerei" constituía una "enfermedad del alma", una "fiebre" surgida en individuos aislados, susceptible de convertirse en epidemia. El objetivo de la filosofía era entonces identificar estos desórdenes mentales a partir de sus síntomas, prevenir la expansión de la enfermedad, y curar a sus eventuales víctimas.

Pero, al igual que Shaftesbury a principios de siglo, Wieland iba 
más allá también de la estigmatización médica. En abierto contraste con su variante negativa, la palabra "Enthusiasmus" debía encarnar por el contrario su revés benéfico: "La Schwärmerei es enfermedad del alma, propiamente una enfermedad del alma, ¡el Entusiasmo es la verdadera vida!"8x. A la manera de los neoplatónicos, el "Entusiasmo" era definido como expresión de todo aquello que es "verdaderamente bueno y bello" en el individuo9x. La presencia de estas cualidades en el hombre constituía así un índice de la presencia de lo divino en el individuo; capaz de provocar en este último un ardor benéfico y amoroso, dirigido a impulsarlo hacia las más altas metas y realizaciones: "y este amor ardoroso por lo verdadero, por lo bello y lo bueno, es propiamente producto de la divinidad, es -tal como dijo Platón- un dios en nosotros"1x0x. La rehabilitación del "Entusiasmo" legitimaba entonces un modelo de autodeterminación basado en las intuiciones estéticas e intelectuales de cada individuo.

Otros autores como Lessing y Herder poseían sin embargo una visión menos optimista de la cuestión. Así, mientras Wieland se esforzaba en distinguir "entusiasmo" y "Schwärmerei", Herder ensayaba el movimiento contrario, al afirmar provocativamente en su escrito "Philosophei und Schwärmerei, zwo Schwestern" (1776) que ambos fenómenos constituían más bien "hermanos espirituales" ("Geistesgeschwistern"), "extremos del espíritu humano", generados recíprocamente: "También la filosofía se alimenta de abstracciones. (...) El Schwärmer quiere ser el más grande filósofo, y el más grande filósofo es el más grande Schwärmer"1x1x. En los términos del argumento herderiano, los "grandes sistemas filosóficos" (Leibniz, Wolff) habían surgido en primera instancia de una multitud de abstracciones conceptuales de carácter arbitrario, por naturaleza tendiente a hundirse en especulaciones fantasiosas, sin conexiones efectivas con la realidad. En consecuencia, pese a sus aspiraciones de transparencia racional, las construcciones sistemáticas de la filosofía también podían ser portadores de un discurso oscurantista y sectario. Más aún, el comportamiento del filósofo no se distinguía de la praxis "entusiasta", sino que por el contrario reproducía sus peores vicios: "Un hombre que habla de una sana razón sin sana razón, que habla sobre conceptos correctos sin correctos conceptos, que reclama una tolerancia infinita con la mayor de las intolerancias, ¿qué otro nombre más gentil 
puede dársele sino el de Schwärmer?"1x2x. El discurso filosófico constituía así otra variante de la omnipresente Schwärmerei que aquejaba a los tiempos ilustrados. No sin ironía, Herder apuntaba mediante este conjunto de fórmulas paradójicas contra las propias pretensiones de los ilustrados berlineses obsesionados en trazar de modo cada vez más dogmático y reactivo la línea de separación entre lo racional y lo no-racional. Invirtiendo los términos de esa obsesión normativista, Herder ofrecía la versión "Sturm und Drang" de la distinción propuesta por Wieland. Razón y sentimiento no debían estar enfrentadas sino reconciliados:

\footnotetext{
"Un hombre, que solamente quiera ser una cabeza, es tan monstruoso, como aquel que solo prefiere a su corazón; un hombre completo es ambas a la vez. Y ser ambas significa que cada una está en su lugar respectivo: el corazón no está en la cabeza, y la cabeza no está en el corazón; precisamente eso muestra su verdadera condición de hombre" $1 \times 3 x$.
}

Lejos así de procurar un ámbito de salvaguarda racional para los lenguajes subjetivos, Herder ofrecía una versión subjetivista de todos los discursos, en la cual aparecían también subsumidas las pretensiones universalistas de la filosofía ilustrada. Vale la pena entonces detenerse en el siguiente punto: cuando Herder extremaba paródicamente los sentidos de la palabra Schwärmerei para identificarlos con la praxis ilustrada anticipaba ya en buena medida la crisis que luego sobrevendría en torno a los significados de la palabra Aufklärung.

Aunque no fuera publicada, la respuesta de Lessing a Wieland escrita en simultáneo a la de Herder, también iba en la misma línea. Para el autor de Nathan der Weise (1799) -no casualmente una obra sobre la tolerancia religiosa- además de pretender poseer revelaciones personales y ser inspirados directamente por Dios, la esencia del Schwärmer radicaba en su tendencia a "hacer enjambre" ["schwärm"] (Lessing, 1979, pp. 548-557). Evocando así la antigua imagen luterana, su escrito "Über eine zeitige Aufgabe" (1776) comenzaba postulando la relación en principio antagónica entre filosofía y discurso entusiasta: por un lado, la actitud distante y reflexiva del filósofo, frente a la exaltación pasional y contagiosa del Schwärmer religioso, siempre a punto de producir caos y desborde social. 
Pero al igual que Wieland y más tarde Garve, Lessing reivindicaba también el entusiasmo especulativo del filósofo. Dicha clase de experiencia era, a fin de cuentas, aquella que hacía posible la existencia de poetas, pintores, y músicos. El filósofo también participaba de ella, y tan sólo debía mantenerse atento a que dicho entusiasmo no lo convirtiera en un entusiasta, "de la misma manera que un catador debía cuidarse de la ebriedad al disfrutar de un buen vino"1x4x. En este punto, al referirse a la pregunta de Wieland, su respuesta formulaba una distinción entre los verdaderos filósofos racionales y los "espíritus luciánicos". Mediante un juego de palabras, Lessing incluso atribuía este comportamiento a sus supuestos críticos "burlones" ("Spotter"), cuya actitud era también "hacer enjambre" mediante la formación de grupos y camarillas. Encerrados en códigos y supuestos propios, pretendidamente racionales, la crítica de los "espíritus luciánicos" a la Schwärmerei carecía de valor argumentativo y, por ende, de efectos persuasivos duraderos.

Por lo que, de manera aparentemente casual, el dramaturgo lanzaba así un comentario mordaz sobre las nuevas formas de sociabilidad emergentes en el seno de la cultura ilustrada y burguesa. Se daba entonces el caso según el cual, en "tiempos filosóficos", ambos roles -los del filósofo entusiasta y el fanático- tendían a converger. En última instancia, ambos reproducían modos de sociabilidad sectarios, indiferentes a la exposición y fundamentación racionales que, para Lessing, debían constituir el núcleo de la verdadera discusión pública. En este punto, incluso el propio orden civil podía verse afectado, al ser dicha confusión de papeles sumamente útil para la difusión de programas subversivos: escondidos detrás de una "máscara más filosófica", nuevos "Schwärmers" predicaban ahora a favor de los "derechos de la humanidad".

Frente a esta nueva clase de entusiastas, Lessing aconsejaba una actitud convenientemente ambigua. El verdadero filósofo debía mantener una simpatía distante, sin dejarse contagiar por su fervor: ya que en última instancia, el individuo racional no era completamente ajeno a aquellos fanáticos; sino que esos últimos eran más bien un "filón" ("Fundgrube") de inspiración constante1x5x, desde cuya base siempre tomaban vuelo las construcciones especulativas del espíritu. El 
filósofo dependía así inexorablemente del Schwärmer al constituir la propia experiencia visionaria la materia prima a partir de la cual surgía el momento necesario de la reflexión. Pero precisamente a raíz de a esta dependencia, el filósofo debía conservar siempre las distancias: este no debía nunca dejarse cautivar por dichas visiones, a fin de no pasar al "enjambre" exaltado en el cual desembocaba inevitablemente todo pensamiento entusiasta, alejado del verdadero "discernimiento" especulativo.

\section{LA CRISIS DE LA ILUSTRACIÓN.}

De modo sintomático, pocos años después, durante la década del ochenta, esta serie de divergencias semánticas conducirían a una nueva crisis lingüística, esta vez desencadenada en torno al sentido de la palabra "Aufklärung". Esta última controversia ponía en duda la confianza optimista característica de algunos representantes eminentes de la Popularphilosophie como Christian Garve, para quien la influencia religiosa había sido definitivamente desplazada por una nueva clase de conocimiento basado en la experiencia racional (Garve, 1785, pp. 19-67)1x6x. Frente a esta confianza, Nicolai, el editor de la Berlinische Monatschrift oponía algunos signos de reserva y alarma1x7x. La situación en Alemania y Europa distaba de estar a la altura del ideal de progreso anhelado por sus pares ilustrados. A diferencia de estos últimos, Nicolai ofrecía un panorama plagado de fenómenos desconcertantes:

"El profeta de la orina Schuppach logra reunir hombres crédulos traídos desde todos los rincones de Europa. Mesmer brinda las más grandes charlatenerías en Viena, y de allí viaja a Paris, prodigando chácharas aún mayores sobre un tipo de magnetismo que ni una sola vez llega a ser tal (...). Saint German es tomado por una especie de dios, y excita la mayor atención por parte de príncipes y otras mentes en absoluto irreligiosas. Cagliostro supo darse el barniz de un hombre extraordinario con flagrantes malabarismos por toda Europa -Lavater inclusomovilizando a hombres de gran importancia. (...). Los admiradores de los fantásticos delirios de Swedenborg se multiplican diariamente; en muchos lugares las banderas del espiritualismo y los visionarios adquieren gran renombre" $1 \mathrm{x} 8 \mathrm{x}$. 
Nicolai comenzaba su enumeración patética con una referencia a Michael Schuppach, el "médico experimental" suizo, conocido por su célebre laboratorio alquímico en Berna. Se daba así una situación contradictoria: mientras los ideales de la Ilustración parecían adquirir voz propia; al mismo tiempo, las fronteras entre la superstición, el ateísmo, y el fanatismo espiritualista comenzaban de pronto a desdibujarse, confluyendo todas estas tendencias dentro de una vasta moda de fraudes y fetichismo intelectual. Tal como hemos sugerido, esta realidad decepcionante fue el motivo que obligó en una primera instancia a explicitar el significado del término "Ilustración". Tanto desde las páginas del Berlinische Monatschrift (publicación insignia de la Popularphilosophie) como desde el seno de la Berliner Mittwochgesellschaft se imponía el debate sobre el sentido de la Ilustración1x9x. La voluntad de saber ("Sapere aude!'), reivindicada por Kant en su célebre ensayo ("Was ist Aufklärung?", 1784)2x0x, no parecía avanzar siempre a lo largo del mismo sendero virtuoso, sino más bien bifurcarse por vías desconocidas o poco confiables. Se trataba por lo demás de una opinión extendida entre los comentaristas de la época. A través de esta nueva proliferación de prácticas y saberes esotéricos, el viejo fanatismo supersticioso se vestía ahora con los colores y las modas de los nuevos tiempos ilustrados:

"Nunca se ha mostrado más vivo el espíritu de secta que en nuestros días, estos tiempos habitualmente denominados 'ilustrados'. Esta adicción casi generalizada por lo maravilloso se ve tremendamente estimulado por el lujo exagerado y los nervios debilitados de la actual generación (...). Loyolistas con túnicas de enfermo y ropas de cotillón, reunidos en coro, Gasnerianos, supersticiosos admiradores de Lavater, martinistas, (...) mesmerianos, sonambulistas, admiradores de Cagliostro, magos, (...), bengelianos, buscadores de la piedra de la sabiduría, (...), cabalistas, (...) y otros asociados cuyos fines ellos mismos ya no conocen, se hallan dispersos por Regensburg y Bayern alternando entre sí, (...) y prestando leal obediencia a los mandamientos de la Schwärmerei"2x1x.

Obsesionado por una supuesta conjura jesuita, próxima a ganarse el favor del futuro regente (Fedérico Guillermo II), el espíritu ilustrado de los berlineses había recaído de pronto en el remolino de las fantasías conspirativas. Como puede verse en este pasaje, a raíz de la oscuridad de sus ideas, los miembros y objetivos de estos múltiples grupos se 
mezclaban indistintamente los unos con los otros. El término "Schwärmerei" apuntaba en este caso a denunciar el imperio caótico de una ola de prácticas y lecturas, muchas veces superficiales y pseudoeruditas, convertidas de pronto en moda intelectual para el público culto. Las consecuencias no eran solo morales, sino también sociales: la superstición y el misticismo Schwärmer, en la casi inabarcable variedad de sus vertientes marginales, tan solo contribuía a reproducir un "espíritu sectario" ("Sektengeist”), cuyo lenguaje enigmático tendía a fragmentar y obturar el cultivo de la "verdadera" discusión pública. No se trataba entonces de una cuestión menor: aquello que se hallaba en discusión era el tipo de "sociedad civil" imaginado por los intelectuales de una burguesía aún en gestación. Se imponía el temor a una conspiración universal liderada por la orden jesuita. En última instancia, la proliferación del fenómeno Schwärmer no hacía más que exacerbar la tendencia a la fragmentación y aislamiento cultural que ya aquejaba endémicamente a los territorios alemanes desde los tiempos de las "guerras de religión".

Paradójicamente, la causa de esta nueva fiebre esotérica se hallaba intrínsecamente asociada al desarrollo cada vez más veloz de aquellos instrumentos comunicativos característicos de la moderna esfera pública burguesa sobre los cuales la propia Ilustración basaba buena parte de difusión en la vida cultural europea (Conrad 2008). En este punto, una serie de transformaciones históricas convergentes habían comenzado a influir cada vez más decisivamente en la cultura europea de la segunda mitad del siglo XVIII. Por un lado, la nueva actitud tolerante de las aristocracias ilustradas y el desarrollo cada vez más vigoroso de una cultura impresa había estimulado la divulgación creciente de un sin número de escritos libertinos, esotéricos, y alquímicos, junto a la ya tradicional circulación de libelos religioso-separatistas. Sumado a ello, el fenómeno de la "adicción a la lectura" (Lesesucht, Lesebegierde) comenzaba a expandirse en diversas partes del continente y estratos sociales, despertando repentinos signos de aprehensión y desconfianza entre las elites letradas (Engelsing, 1974, Faulstisch, 2002)2x2x. Así, por ejemplo, en una carta dirigida a su biógrafo Ludwig E. Borowski (1740-1831), la cual figuraría como una introducción al escrito de este último sobre Cagliostro, Kant atribuía la fascinación del público por dichos personajes excéntricos a "la manía de la lectura universalmente 
diseminada" y a su causa material, la "Buchmächerei" (Kant, 1868, pp. 314-320)2x3x.

La crisis de la ilustración surgía entonces de una nueva ampliación de los significados de la palabra "Schwärmerei": si en su marco luterano original dicho término había servido para subsumir una multitud de expresiones religiosas marginales; en la segunda mitad del siglo XVIII, con la expansión de la cultura impresa, dicho término incluirá todas aquellas manifestaciones de la espiritualidad marginales o minoritarias (alquimia, esoterismo, neoplatonismo, guyonismo) cultivadas cada vez con mayor vehemencia por los miembros del mundo burgués y aristocrático. En el marco de este proceso, la pluralización de prácticas, lecturas, y creencias conducirá muy pronto a la logomaquia: "Pietist", "Fanatiker", "Enthusiast", "Schwärmer", "mystisch", "Böhmisten", "Weigelianer", "Schwenckfeldianer", "Labbadisten", etc.; todas estas expresiones eran en sí mismos términos indistintos e intercambiables, imposibilitados en esencia para establecer alguna distinción crítica o cognoscitiva relevante. En palabras del Popularphilosoph Garve: "Todo lo excéntrico se halla más o menos en peligro de denominarse 'Schwärmer'" $2 \mathrm{x} 4 \mathrm{x}$. Las connotaciones generalizadoras del término "Schwärmerei" se habían vuelto así repentinamente contraproducentes: a partir del desarrollo acelerado de la nueva cultura editorial (Buchmächerei), sus manifestaciones pasaban a ser cada vez más difíciles de definir a priori. ¿Adónde comenzaba y dónde terminaba la Schwärmerei? ¿Cómo distinguir entre aquello que era y no era Ilustración?

\section{CONCLusiones}

A lo largo del presente artículo hemos visto hasta qué punto un conjunto de controversias semánticas y usos conceptuales desplegados en torno al fenómeno entusiasta determinaban toda una serie de posicionamientos en torno al sentido del proceso ilustrado. Los presupuestos de la crisis de significado que en la década del ochenta surgiría alrededor de la palabra "Aufklärung" ya estaban enraizados en los intentos de rehabilitación filosófica de la palabra "Entusiasmo" ("Enthusiasmus") y sus respectivas delimitaciones frente a su 
equivalente negativo (el término "Schwärmerei"), acontecidos algunos años antes, durante la década del setenta. Así, tal como hemos visto en la discusión de Wieland con el Sturm und Drang, el "Entusiasmo" constituía en este punto un ideal posible de racionalidad concebido a partir de un nuevo modelo de subjetividad. Por su parte, otros autores como Herder y Lessing también recurrían al subjetivismo esotérico del "entusiasmo fanático" (Schwärmerei) para formular sus propios

74 cuestionamientos al discurso y la sociabilidad ilustrada. Estas críticas ya advertían por cierto la crisis posterior del proyecto racionalista. Ya que más tarde, será la propia ampliación de significados atribuídos a la palabra Schwärmerei uno de los motivos principales que terminarían obliterando las condiciones del debate. La Schwärmerei se convertía así en "lo otro" de la Razón; un epíteto peyorativo cuyo carácter polisémico constituía una respuesta a la democratización de los hábitos de lectura producidos por la nueva cultura impresa. Precisamente a partir de estos intentos de delimitación desesperados, se imponía una visión conspirativa tendiente a englobar una multiplicidad de manifestaciones culturales dentro de un solo término. De este modo, los alcances del discurso racional, su capacidad finita para subsumir de modo coherente posiciones heterogéneas evitando el gesto arbitrario de la exclusión dogmática, aparecía puesto a prueba a través de este conjunto de tensiones semánticas.

\section{BibLIOGRAFÍA}

ANÓNIMO, Neuer Beitrag zu einiger Kenntniß verschiedener jetzt existirenden Geheimen Gesellschaften. Berlinische Monatschrift ${ }^{\circ} 6$, 1785, pp. 355-374.

BEISER, Frederick, The Fate of Reason, German Philosophy from Kant to Fichte. Cambridge, Massachusetts: Harvard University Press, 1987.

BEZOLD, Raimund, Popularphilosophie und Erfahrungsseelenkunde im Werk von Karl Philipp Moritz. Würzburg: Könighausen \& Neumann, 1984.

CONRAD, Anne, Rationalismus und Schwärmerei. Studien zur Religiosität und Sinndeutung in der Spätaufklärung. Hamburg: DOBU Verlag, 2008.

DAHNKE, Hans-Dietrich, “ Was ist Aufklärung?". En: DAHNKE HansDietrich et al. (eds.), Debatten und Kontroversen. Literarische Auseinandersetzungen in Deutschland am Ende des 18. Jahrhunderts. 
Berlin-Weimar: Aufbau Verlag, 1989, pp. 39-134.

ENGEL, Manfred, Die Rehabilitation des Schwärmers. En: SCHINGS HansJürgen (edit.) Der ganze Mensch. Stuttgart: Metzler, 1994, pp. 469-498.

ENGELSING, Rolf, Der Bürger als Leser. Lesergeschichte in Deutschland 1500-1800. Stuttgart: Metzler, 1974.

FAULSTISCH, Werner, Die Bürgerliche Mediengesellschaft (1700-1830). Göttingen: Vandenhoeck \& Ruprecht, 2002.

GANTET, Claire, Der Traum in der Frühen Neuzeit. Ansätze zu einer kulturellen Wissenschaftsgeschichte. Berlin: de Gruyter, 2010.

GARVE, Christian. Bemerkungen über die Neigungen der Menschen zum Wunderbaren und über den Zweck dieses Zuges in der menschlichen Natur. Deutsches Museum, Leipzig, Bd. 1, Januar-Juni 6, p. 517-528, 1778.

HERDER, Johann G., "Philosophie und Schwärmerei, zwo Schwestern". En: SUPHAN Bernhard (ed.), Herders Sämmtliche Werke, B. 9. Berlin: Weidmann, 1877-1913, pp. 497-498.

HEINZ, Jutta, Eine Art - wie der Merkur hätte werden sollen: Programmatik, Themen und kulturpolitische Positionen des Teutschen Merkur und des Deutschen Museum im Vergleich. En: HEINZ Andrea (ed.), Der Teutsche Merkur - die erste deutsche Kulturzeitschrift. Heidelberg: Universitätsverlag Winter, 2003, pp. 108-130.

KAUFMANN, Thomas, Nahe Fremde. Aspekte der Wahrnehmung der 'Schwärmer' im frühneuzeitlichen Luthertum. En: GREYERZ v. et al. (eds.). Interkonfessionalität, Transkonfessionalität, binnenkonfessionelle Pluralität. Neue Forschungen zur Konfessionalisierungsthese. Heidelberg: Gütersloher Verlagshaus, pp. 179-241, 2002.

KANT, Immanuel, Über die Buchmächerei: Zwei Briefe an Herrn Friedrich Nicolai. En: HARTENSTEIN Gustav (ed.) Immanuel Kant's sämmtliche Werke. Bd. 17. Schriften, 1797-1800, pp. 314-320, 1868.

KANT, Immanuel, Beantwortung der Frage: Was ist Aufklärung?. En: WEISCHEDEL Wilhelm (ed.) Kant Werke, Bd.9. Darmstadt, Wissenschaftliche Buchgesellschaft, pp. 51-61, 1968.

LA VOPA, Anthony, KLEIN, Lawrence, Enthusiasm and Enlightenment in Europe, 1650-1850. San Marino: Huntington Library, 1998.

LESSING, Gotthold E., Über eine zeitige Aufgabe: Wird durch die Bemühungen kaltblütiger Philosophen und Lucianischer Geister gegen das, was sie Enthusiasmus und Schwärmerey nennen, mehr Böses als Gutes stiftet? und in welchen Schranken müßten sich die Antiplatoniker und Luciane halten, um nützlich zu seyn?. En: EIBL Karl et al. (eds.) 
Werke. B. 8: Theologiekritische Schriften 3, Philosophische Schriften. München: Carl Hanser Verlag, pp. 548-557, 1979.

MAURER, Michael, Die Biographie des Bürgers. Lebensformen und Denkweisen in der formativen Phase des deutschen Bürgertums (16801815). Göttingen: Vandenhoeck \& Ruprecht, 1996.

OUTRAM, Dorinda, La Ilustración. México: Siglo XXI, 2011.

PIKULIK, Lothar, Leistungsethik contra Gefühlskult. Über das Vehältnis von Bürgerlichkeit und Empfindsamkeit in Deutschland. Göttingen: Vandenhoeck \& Ruprecht, 1984.

REDEKOP, Benjamin W., Enlightenment and Community. Lessing, Abt, Herder, and the quest for a german public. Quebec: McGill-Queen's University Press, 2000.

WIELAND, Christoph Martin , Eines ungenannten Antwort. En: MANGER Klaus et. al. (eds.), Werke Bd. 1. Berlin: Walter de Gruyter, 2010, pp. 351-361.

WIELAND, Christoph M. "Fragen". Der Teutsche Merkur, Weimar, 1. Vierteljahr, enero de 1776, p. 82.

\section{Notas}

1 "Las cada vez más escépticas y grises representaciones asociadas a la imaginación [Einbildungskraft] a partir de mediados del siglo XVIII desembocaron en la percepción de que las visiones, sueños, y éxtasis del Schwärmer no eran solamente vividas como experiencias sino como hechos verdaderos" (Gantet, 2010, p.450).

2 "Wird durch die Bemühungen kaltblütiger Philosophen und Lucianischer Geister gegen das, was sie Enthusiasmus und Schwärmerey nennen, mehr Böses als Gutes stiftet? und in welchen Schranken müßten sich die Antiplatoniker und Luciane halten, um nützlich zu seyn?" (Wieland,1776, p. 82). Para una reconstrucción pormenorizada de la discusión: Engel, 1994, pp. 469498, y Heinz, 2004, pp. 108-130.

3 "Enthusiasmus, Schwärmerei - wes geistes Kind? (...) Wunderbar, daß bey aller Definitionslust und Gabe der kaltblütigen Philosophen noch keine bestimmte, feste, sichere, anwendbare Definition da ist, von der man ausgehe (...)" (Wieland, 2011, p. 173).

4 "Sie seufzen ist inniglich über ein gewißes Feuer, das in Teutschlands Jünglingen wüthe, selbst Männer zu Jünglingen 
schaffe; -über die Schnellkraft und dem Empfindungsstrom, von dem sich alles hinreißen laße". Id.ibid., p. 174.

5 Cabe mencionar la obra de Nicolai Die freuden des jungen Werthers. Leiden und Freuden Werthers des Mannes (1775), así como también Etwas über die leiden des jungen Werthers: und über die freuden des jungen Werthers (Christian A. Bertram 1775), Etwas über die Leiden und Freuden des jungen Werthers (publicada con el seudónimo "Johann Bernhard Wilhelm von Hymmen", 1775), y Über die Leiden des jungen Werthers: Gespräche. (Johann C. Riebe, 1775).

6 "Ich nenne (...) Schwärmerei eine Erhitzung der Seele von Gegenständen, die entweder gar nicht in der Natur sind, oder wenigstens das nicht sind, wofür die berauschte Seele sie ansieht". (Wieland, 1827, pp. 181182).

7 "Dem Worte Schwärmerei (...) entspricht das Wort Fanatismus ziemlich genau; wiewohl diez letztere durch den Gebrauch einer besonderen Gattung vom Schwärmerei, nämlich der religiosen, zugeeignet worden ist". Id.ibid., p. 181.

8 "Schwärmerei ist Krankheit der Seele, eigentliches Seelenfieber; Enthusiasmus ist ihr wahres Leben!". Id.ibid. p. 181.

9 "was wahrhaft schön und gut ist". Id.ibid. p. 181.

10 "und diese feurige Liebe zum wahren, Schönen und Guten ist ganz eigentlich Einwirkung der Gottheit, ist (wie Plato sagt) Gott in uns". Id.ibid. p. 182.

11 "Philosophie nährt sich von Abstractionen, Schwärmerei auch. (...) Der Schwärmer will der größte Philosoph sein, und der größte Philosoph ist der größte Schwärmer". (Herder, 1913, pp. 497-498).

12 "Ein Mensch, der von gesundem Verstande ohne gesunden Verstand, von richtigen Begriffen ohne richtigen Begriff, von ewiger Toleranz mit möglichster Intoleranz spricht, welchen gelindern Namen kan er sich versprechen als Schwärmer?". Id.ibid., p. 497.

13 "Ein Mensch, der allein Kopf sein will, ist so ein Ungeheuer, als der allein sein Herz will; der ganze Mensch ist beides. Und daß er Beides ist, jedes an seiner Stelle, das Herz nicht im Kopf, den Kopf nicht im Herzen, das eben zeigt ihn als Menschen." Id.ibid., p. 498.

14 "So wie der feine Wollüstling, dem der Wein schmeckt, und der gern unter Freunden sein Gläschen leeret, sich wohl hüten wird, ein Trunkenbold zu werden". Id.ibid., p. 552.

15 Id.ibid., p. 553.

16 Para una reconstrucción del debate en torno a los significados de la Ilustración, Dahnke, 1989, pp. 39-134.

17 Id.ibid., p. 109.

18 "Der Urinprophet Schuppach zog von allen Enden von Europa 
leichtgläubige Menschen zusammen. Mesmer machte in Wien mit Magnetenkuren die größten Charlatanerien, geht von da nach Paris, macht noch grössere Charlatanerien mit einem Magnetismus der nicht einaml magnetisch ist (...). Saint German ward für einen Gott ausgegeben, und erregte die Aufmerksamkeit vieler Fürsten und anderer gar nicht geistlosen Köpfe. Cagliostro wuste mit offenbaren Gaukleyen in ganz Europa, und auch bey Lavatern sich den Anstrich eines ausserordentlichen Mannes zu geben, und setzte Männer von der größten Bedeutung in Bewegung. (...) Die Anhänger von Swedenborgs tollen Schwärmereyen vermehren sich täglich, Geisterbanner und Geisterseher sind an sehr viel Orten im größten Ansehen" (Nicolai, 1786, p. 108).

19 Ibid. Dahnke, pp. 39-42.

20 Kant, 1983, pp. 51-61.

21 "Nie hat sich der Sektengeist thätiger gezeigt, als in unsern Tagen, welche man die aufgeklärten nennt (...) Dieser fast allgemeine Hang zm Wunderwaren wird durch den alle Kräfte der Erwerbung übersteigenden Luxus, und durch das geschwächte Nervensystem der jetzigen Generation ungemein befördert (...). Lojolisten im gestiken Kleide, im Chorgewand, und im einfachen Kittel des Bedürfnisses; Gasnerianer; Lavaterische Glaubenschwärmer; Martinisten, Insoucians; Mesmerianer; Somnambulisten; Anhänger von Cagliostro; Schröpferische Magier; Crusianische Magier; Bengelianer; Den Stein der Weisen suchende Rosenkreuzer; Lammsbrüder, die sich von innerm Stolze nähren; Illuminaten und Minervalen; Kabbalisten; Verehrer des verunglükten Erziehers Bahrdt; und andere Verbundene, die den Zwek ihrer Vereinigung (...) nicht mehr wissen; finden sich in Regensburg und Baiern zerstreuet, um einander wechselseitig (...) nach den ächten Grundsätzen der Schwärmerei zu verfolgen". Anónimo, "Neuer Beitrag zu einiger Kenntniß verschiedener jetzt existirenden Geheimen Gesellschaften", en Berlinische Monatschrift 6, 1785.

22 En última instancia, dicho temor se originaba en las potenciales consecuencias negativas que los nuevos hábitos de lectura podrían tener en la productividad de los individuos pertenecientes al campesinado y el artesanado (Schenda, 1970, p. 95).

23 Sobre la posición de Kant ante el mercado editorial, cf. "Über die Buchmächerei: Zwei Briefe an Herrn Friedrich Nicolai", en Kant, 1983, pp. 431-438.

24 "Alles Excentrische ist mehr oder weniger in Gefahr, schwärmerisch zu seyn" (Garve, 1778, p. 521) 